\title{
Hepatitis B Virus (HBV) Serological Patterns in Benue State, Nigeria
}

\author{
Emmanuel Msugh Mbaawuaga ${ }^{*}$, Christian Ukuoma Iroegbu², Anthony Chibuogwu Ike ${ }^{3}$ \\ ${ }^{1}$ Department of Biological Sciences, Benue State University, Makurdi, Nigeria \\ ${ }^{2}$ Cross River University of Technology, Calabar, Nigeria \\ ${ }^{3}$ Department of Microbiology, University of Nigeria, Nsukka, Nigeria \\ Email: ${ }^{*}$ msughawuaga@yahoo.com
}

Received 12 October 2013; revised 12 November 2013; accepted 19 November 2013

Copyright (C) 2014 by authors and Scientific Research Publishing Inc.

This work is licensed under the Creative Commons Attribution International License (CC BY). http://creativecommons.org/licenses/by/4.0/

(c) (i) Open Access

\section{Abstract}

A total of 1535 randomly collected blood specimens from different groups of consenting subjects in Benue State, were screened by ELISA for Hepatitis B surface antigen (HBsAg), hepatitis B surface antibodies (HBsAb), hepatitis B core antibodies (HBcAb), hepatitis Be antigen (HBeAg) and Hepatitis B core IgM antibodies (HBcIgM). The pattern of occurrence of these HBV markers in each blood sample was used to determine individuals with current, acute or chronic infection histories. Of the 1535 sampled individuals, 1319 (85.9\%) showed a serological evidence of exposure to $\mathrm{HBV}$ infection, some through natural infection $(22.7 \%)$ and others $(13.0 \%)$ through vaccination; $12 \%$ of the exposed were inferred to be currently infected and $91.2 \%$ chronically infected. Hepatitis delta virus (HDV) antigen was also detected in $2.7 \%$ of the HBsAg positive individuals; and was encountered more (6.7\%) in those with acute hepatitis than those with chronic disease. Thus, there are apparently healthy persons with acute and chronic HBV and HDV infection who may serve as source of infection to others. This calls for a government organized Hepatitis Programme to treat cases of acute and chronic hepatitis and roll out strategy for preventing the spread of HBV infections.

\section{Keywords}

HBV Markers; Acute HBV; Chronic HBV; HDV; Benue State

\section{Introduction}

Hepatitis B virus (HBV), Hepadnaviridae, is the leading cause of chronic liver disease and liver related death

${ }^{*}$ Corresponding author. 
worldwide, with the majority of these cases occurring in areas of Africa and Asia [1]. Outcome of infection by the non-cytopathic, hepatotrophic HBV depends on the quality and strength of the antiviral immune response [2]. The most common outcome after infection is the expression of diverse serological markers of varying epidemiological and clinical significance namely, Hepatitis B surface antigen (HBsAg), Hepatitis B surface antibody (HBsAb), Hepatitis B core antibody (HBcAb), Hepatitis B early antigen (HBeAg), Hepatitis Be antibody (HBeAb) and Hepatitis B core IgM antibody (HBcIgM) [3].

Symptomatic and asymptomatic forms of both acute and chronic infections may be discovered incidentally only through laboratory assay of these viral markers. These markers may occur singly or in various combinations depending on the natural history of the infection [3].

Early in the course of HBV infection, HBsAg is present in the serum and disappears with the production of specific antibodies against it and eventual recovery from the disease. HBeAg appears early in acute infection and is associated with high rate of infectivity and higher chances of chronicity, but may also recede on seroconversion to e antibodies (anti-HBe). Hepatitis B core antigen (HBcAg) is not detectable in the blood stream; however, detection of antibodies to HBcAg (anti-HBc) of the IgM (anti-HBcIgM) and IgG (anti-HBcIgG) classes suggests acute or chronic infection [3].

Hence, detection of these markers and the serological patterns they present in individuals help to determine stages of HBV infection and plan better management strategies.

Another factor is that HBV infections often occur concomitantly with a defective virus, the Hepatitis delta virus (HDV). These co-infections usually resolve, however, super-infection frequently results in chronic HDV infection and chronic active hepatitis or fulminating hepatitis in HBV infected individuals [3]. Several prevalence studies have been carried out among such subject as patients with chronic hepatitis, intravenous drug users (IDUs), homosexuals and sex workers [4] but these may not be representative of the normal community, particularly in Africa.

In Nigeria, HDV has been reported to contribute significantly to HBV morbidity and mortality with $4.3 \%$ antibody prevalence among asymptomatic and $15.0 \%$ among patient with chronic hepatitis, liver cirrhosis and primary liver cell carcinoma in University of Nigeria Teaching Hospital Enugu [5]. However, there is paucity of information about HBV/HDV antigen detection in Benue State and Nigeria as a whole.

Hence, the work reported here set out to screen for HBV exposure, determine the pattern of occurrence of the HBV infection markers with one another and with HDV; and predict the state of HBV infection in the individuals sampled.

\section{Materials and Methods}

\subsection{Study Area}

The study covers the three senatorial district of Benue State of Nigeria: Benue North East Senatorial district (Ukum, Logo, Katsina-Ala, Ushongo, Konshisha and Vandekya local Government Areas), Benue North West Senatorial district (Gboko, Tarka, Makurdi, Guma, Gwer West and Gwer East LGAs) and Benue South Senatorial district (Oju, Obi, Otukpo, Ado, Apa, Agatu, Okpokwu, Ohimini and Ogbadibo LGAs) designated as Zones A, B and C, respectively.

Benue State is situated between longitude $7^{\circ} 40^{\prime} \mathrm{E}$ and $10^{\circ} 00^{\prime} \mathrm{E}$, latitude $6^{\circ} 30^{\prime} \mathrm{N}$ and $8^{\circ} 24^{\prime} \mathrm{N}$. Its population stands at 4,253,641 by the 2006 population census figures [6], with a land mass of 31,400 sq kilometres.

Inhabitants are predominantly farmers, with few civil servants and traders and as it is with most areas engaged in subsistent farming, they are low income earners. The literacy rate in the area is low; and the dominant ethnic nationalities are Tiv and Idoma. The Tivs live in dispersed habitations, the Idomas and less populous Igede people live in compounds in clustered patterns [7].

\subsection{Ethical Clearance}

Ethical clearance was sought and obtained from Benue State Ministry of Health and Human Services Makurdi. For reasons of confidentiality all data were kept anonymous in accordance with World Medical Association (WMA) declaration of Helsinki [8].

All participants voluntarily signed consent forms either in own handwriting or with thumb prints as evidence of willingness to provide samples for the tests. While responses to structured questionnaire administered in Eng- 
lish but explained to the illiterates among them in local dialects were used to obtain demographic data, history of transfusion and of HBV vaccination.

\subsection{Selection of Sample Population and Specimen Collection}

Health service based selection of subjects was adopted for groups such as pregnant women, blood donors, Health care workers and automobile accident victims for easy identification and accessibility while sex workers were drawn by community based selection. Two Local Government Areas from each of the three senatorial districts: Benue North east (Zone A), Benue North West (Zone B) and Benue South (Zone C) were selected.

Sample collection and analysis was carried out between January, 2011 and June, 2013.

Following counselling concerning the nature and use of the specimen to be collected, 4 - $5 \mathrm{ml}$ of venous blood was asceptically taken from each of the 1535 participant by venepuncture from the cubical fossa and discharged into a vacutainer. The blood was allowed to clot and centrifuged at $1000 \mathrm{~g}$ for ten minutes. Serum was aspirated with Pasteur pipettes and was stored in sample vials at $-17^{\circ} \mathrm{C}$ if not used immediately.

\subsection{Assay of Blood Samples for HBV Serological Markers}

All Sera were assayed for three Hepatitis B virus markers-Hepatitis B surface antigen (HBsAg), Hepatitis B surface antibody (anti-HBs) and Hepatitis B core antibody (anti-HBc). Sera that were reactive for HBsAg were further tested for Hepatitis B early antigen ( $\mathrm{HB} e \mathrm{Ag}$ ) and $\mathrm{HBcIgM}$. HBsAg positive sera were also screen of Hepatitis D virus (HDV) antigens.

Two assay techniques were adopted to determine presence and level of HBV markers in serum: a direct antigen-antibody-antigen "Sandwich" method (for HBsAg, HBsAb, HBeAg and HDV antigen); and an indirect antigen-antibody-antibody assay method for $\mathrm{HBcAb}$. The sandwich ELISA method contains polystyrene microwell strips pre-coated with monoclonal antibodies specific to HBsAg, HBeAg, HBcIgM and HDVAg or antigen specific to HBs recombinant monoclonal antibodies detectable in serum samples.

Micro-plate incubator with a shaker and a timer (Model: STAT FAX 2200, Awareness Technology Inc., USA) was used for micro-plate incubation in line with assay incubation temperature and time as specified by ELISA kit manufacturer while the micro-plate was washed 5 times using an automated micro-plate washer (Model: STAT FAX 2600, Awareness Technology, USA). The absorbance was measured using double filters at 450 and $630 \mathrm{~nm}$ respectively in an automated microplate reader (Model: Stat Fax 2100, Awareness Technology Inc., USA).

The cut-off for each batch was calculated using the mean optical densities of the negative control in accordance with the manufacturer's instruction. This cut-off value was then used to calculate the activity index for each sample by dividing the mean OD of each sample with the cut-off value. Samples with the activity index values higher or equal to those of positive control were considered positive, while those with values below were reported as negative.

\section{Results}

After the serological screening of 1535 participants for the three major markers, a combination of these markers simultaneously was used in determining, current infection, previous but recovered infection with or without protective antibodies, or no history of HBV infection [3].

The tabulation in Table 1 shows the serological patterns encountered with their interpretations.

Further investigation of currently infected subjects using additional HBV markers (HBeAg and HBcIgM) generated the serologic patterns of HBV presented in Table 2.

Considering these markers singly, HBsAg was observed in $12.0 \%$ of the subjects, HBsAb in $36.7 \%$ while $\mathrm{HBcAb}$ was detected in $82.5 \%$. The total exposure rate of the participants was $85.9 \%$.

A deduction from the interpretation of the serological patterns (Table 3) shows that $184(12.0 \%)$ of the 1535 subjects were currently infected with HBV, 548 (35.7\%) were inferred to be exposed and immune, out of which $13.0 \%$ reported being vaccinated against HBV but $22.7 \%$ had no previous HBV vaccination; 587 (38.2\%) were only positive for HBcAb antibodies and represent those with waned immunity and 216 (14.1\%) were those with no previous exposure to HBV. A total of 345 (22.5\%) reported received at least one dose of HBV vaccine previously while 1190 (77.5\%) were those with no history of HBV vaccination. 
Table 1. Frequency of occurrence of the pattern of the three HBV markers and their interpretation.

\begin{tabular}{|c|c|c|}
\hline Serologic Patterns & Frequency (\%) Occurrence & Interpretation \\
\hline $\mathrm{HBsAg}^{+}, \mathrm{HBsAb}^{-}, \mathrm{HB} \mathbf{A b}^{+}$ & $175(11.4)$ & Current Infection \\
\hline 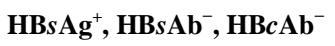 & $9(0.6)$ & Current Infection \\
\hline $\mathrm{HB} \mathrm{Ag}^{-}, \mathrm{HB} \mathrm{Ab}^{+}, \mathrm{HB} \mathrm{Ab}^{+}$ & $504(32.8)$ & Exposed Immune \\
\hline $\mathrm{HBsAg}^{-}, \mathrm{HBsAb}^{+}, \mathrm{HBcAb}^{-}$ & $44(2.9)$ & Exposed Immune \\
\hline $\mathrm{HBsAg}^{-}, \mathrm{HBsAb}^{-}, \mathrm{HBcAb}^{+}$ & $587(38.2)$ & Waned Immunity \\
\hline $\mathrm{HB} \mathrm{Ag}^{-}, \mathrm{HB} \mathrm{Ab}^{-}, \mathrm{HB} \mathrm{Ab}^{-}$ & $216(14.1)$ & None Exposed to HBV \\
\hline Total & $1535(100)$ & Endemic HBV \\
\hline
\end{tabular}

Using Table of interpretation. WHO/CDS/CSR/LYO/ 2002.2: Hepatitis B. http://www.who.int/emc.

\begin{tabular}{|c|c|c|}
\hline Serological Patterns Observed & Frequency $(\%)$ Occurrence & Interpretation \\
\hline $\mathrm{HBsAg}^{+}, \mathrm{HBsAb}^{-}, \mathrm{HBcAb}^{-}, \mathrm{HBeAg}^{-}, \mathrm{HBcIgM}^{-}$ & $6(3.3)$ & Acute Infection \\
\hline $\mathrm{HBsAg}^{+}, \mathrm{HBsAb}^{-}, \mathrm{HBcAb}^{+}, \mathrm{HBeAg}^{+}, \mathrm{HBcIgM}^{+}$ & $10(5.5)$ & Acute Infection \\
\hline $\mathrm{HBsAg}^{+}, \mathrm{HBsAb}^{-}, \mathrm{HBcAb}^{+}, \mathrm{HBeAg}^{+}, \mathrm{HBcIgM}^{-}$ & $7(3.8)$ & Chronic $\mathrm{HBeAg}^{+}$ \\
\hline $\mathrm{HBsAg}^{+}, \mathrm{HBsAb}^{-}, \mathrm{HBcAb}^{+}, \mathrm{HBeAg}^{-}, \mathrm{HBcIgM}^{+}$ & $124(67.8)$ & Chronic Carriers \\
\hline $\mathrm{HBsAg}^{-}, \mathrm{HBsAb}^{-}, \mathrm{HBcAb}^{+}, \mathrm{HBeAg}^{-}, \mathrm{HBcIgM}^{-}$ & $36(19.7)$ & Chronic Carriers \\
\hline Total & $183(100)$ & Endemic HBV \\
\hline
\end{tabular}

Using Table of interpretation. WHO/CDS/CSR/LYO/ 2002.2: Hepatitis B. http://www.who.int/emc.

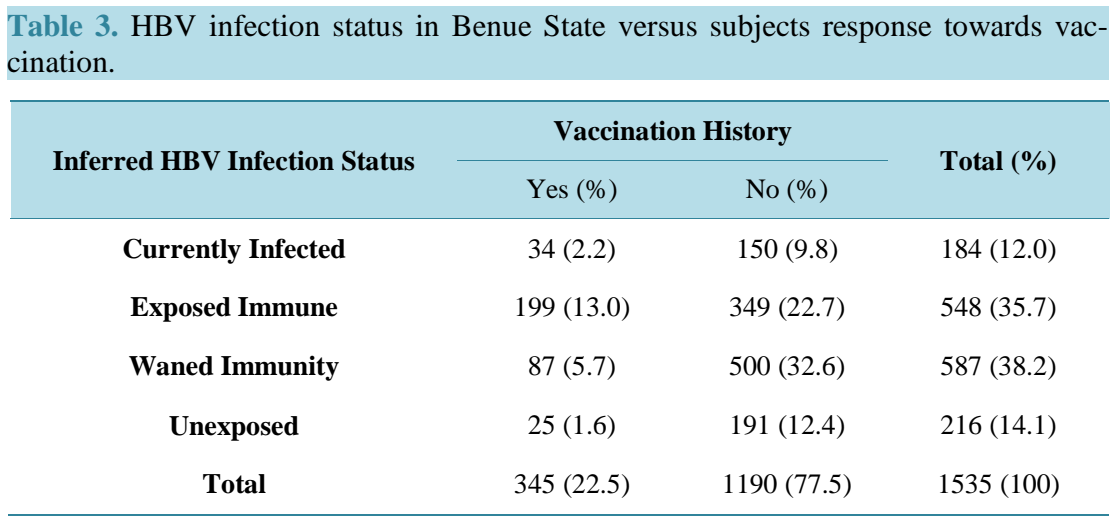

The frequency of occurrence of HBV current infections among the studied subjects (Figure 1) show acute infection in $8.7 \%$, chronic HBeAg positivity in 3.8\% while $87.4 \%$ were chronic carriers with negative HBeAg.

Table 4 describes the gender classification of HBV current infections among the studied subjects in Benue State. Acute and chronic HB was higher in males but healthy HBV carriers were more in females $(\mathrm{P}>0.05)$.

Presence of the antigen of infectivity (HBeAg) was also higher in males ( $\mathrm{P}>0.05)$ than females while Hepatitis delta virus (HDV) antigen detected only in females ( $\mathrm{P}>0.05$ ) (Table 5). The 6.2\% HDV antigen positive individuals apparently had acute HBV infection, while $2.5 \%$ prevalence was observed among the chronic HBV carriers. HDV infection was detected significantly more (60.0\%) in those with history of blood transfusion than in those with no history of transfusion $(\%),(P=0.002)$.

As shown in Table 6 there were more individuals with current infection (16.7\%) as well as the unexposed 


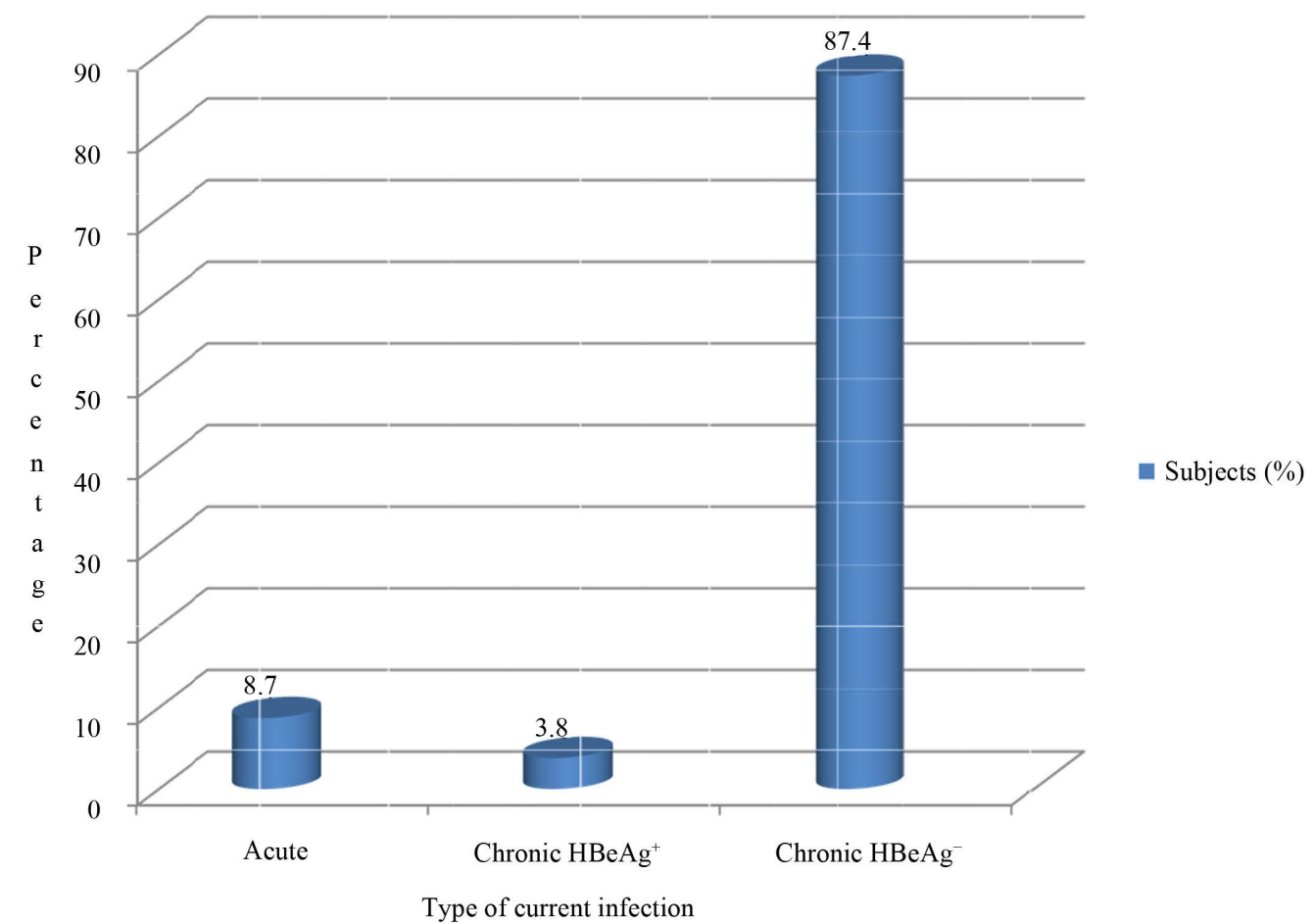

Figure 1. Frequency of occurrence of HBV current infections among subjects in Benue State, 2013, NB: This figure is the result of the interpretation of serological patterns in Table 2.

Table 4. Classification of HBV current infection in respect to sex of the subjects in Makurdi.

\begin{tabular}{ccccc}
\hline Sex & Number Tested & Acute HBV & Chronic $\mathbf{H B e A g}{ }^{+}$ & Chronic $\mathbf{H B e A g}^{-}$ \\
\hline Male & 67 & $7(10.4)$ & $4(6.0)$ & $56(83.6)$ \\
Female & 116 & $9(7.8)$ & $3(2.6)$ & $107(89.7)$ \\
Total & 183 & $16(8.7)$ & $7(3.8)$ & $160(87.4)$ \\
\hline
\end{tabular}

$\chi^{2}=1.802, \mathrm{df}=2, \mathrm{P}=0.406$.

Table 5. Sex distribution of HBeAg and HDV among HBsAg positive subjects in Benue State.

\begin{tabular}{cccc}
\hline Sex & Number Tested & $\mathbf{H B e A g}^{+} \mathbf{( \% )}$ & $\mathbf{H D V}^{+} \mathbf{( \% )}$ \\
\hline Male & 67 & $8(11.9)$ & $0(0.0)$ \\
Female & 116 & $9(7.8)$ & $5(4.3)$ \\
Total & 183 & $17(9.3)$ & $5(2.7)$ \\
& & $\chi^{2}=0.881$ & $\chi^{2}=2.969$ \\
& & $\mathrm{df}=1$ & $\mathrm{df}=1$ \\
& & 0.348 & 0.085 \\
\hline
\end{tabular}

(41.7\%) in those aged 13 years and below than in the higher age brackets; the latter had more people with only $\mathrm{HBcAb}$ showing waning immunity? Past infections were highest with 50 - 59 age category (46.8\%), followed by 40 - 49 with $42.9 \%$. The relationship between HBV infection status and age was highly significant statistically $(\mathrm{P}=0.001)$. 
The distribution of the HBV infection status with respect to the categories of the samples studied is as shown in Table 7. Lowest current infections were recorded in pregnant women (7.5\%) while the highest was found among Sex workers (16.9\%). Past infections were observed more among Health care workers (44.3\%) followed by prospective blood donors (44.0\%). Automobile accident victims had the highest number of unexposed subjects (17.7\%), followed by pregnant women while the least unexposed were the patients (11.9\%). However, pregnant women had the highest number of subjects with only HBcAb detection.

\section{Discussion}

The current infection of $12.0 \%$ for HBV as determined by the serological pattern obtained in this study falls within the range of previously reported findings by Mbaawuaga et al. [9] [10] for pregnant women (11\%) and hospital patients (12.0\%), but lower than the $20.0 \%$ observed by Alao et al. [11] and 39.0\% by Amuta et al. [12] among blood donors and hospital patients, respectively, in the same region. Although high prevalence of HIV in Benue State has often been attributed to cultural habits such as un-protected sex at night gatherings including during burial night wake keepings [13], low literacy and poverty [7]; it is not clear whether HBV which have similar mode of transmission and associated risk factors like HIV will share in these attributes.

Similar findings have been reported in other North central states of Nigeria where HIV prevalence is highest. Prevalence of $14.0 \%, 23.0 \%, 17.1 \%, 15.1 \%$ and 25.05 have been reported by Sule et al. [14] in Kogi state, Forbi et al. [15] and Adoga et al. [16], respectively, in Nasarawa State, Egah et al. [17] and Uneke et al. [18], respectively, in Jos, Plateau State.

Table 6. Distribution of HBV Status in age among subjects in Benue State, Nigeria.

\begin{tabular}{ccccc}
\hline \multirow{2}{*}{ Age Group } & Number Tested & \multicolumn{3}{c}{ Infection Classification } \\
\cline { 3 - 5 } & 12 & Current infection (\%) & Past Infection (\%) & Unexposed (\%) \\
\hline Below 13 & 125 & $14(11.2)$ & $4(33.3)$ & $5(41.7)$ \\
$\mathbf{1 3}-\mathbf{1 9}$ & 828 & $104(12.6)$ & $58(70.4)$ & $23(18.4)$ \\
$\mathbf{2 0}-\mathbf{2 9}$ & 344 & $37(10.8)$ & $253(73.5)$ & $140(16.9)$ \\
$\mathbf{3 0}-\mathbf{3 9}$ & 119 & $17(14.3)$ & $96(80.7)$ & $6(15.7)$ \\
$\mathbf{4 0}-\mathbf{4 9}$ & 79 & $10(12.7)$ & $63(79.7)$ & $6(7.6)$ \\
$\mathbf{5 0}-\mathbf{5 9}$ & 28 & $0(0.0)$ & $26(92.9)$ & $2(7.1)$ \\
$\mathbf{6 0}$ \& Above & 1535 & $184(12.0)$ & $1115(72.6)$ & $236(15.4)$ \\
\hline Total & & & & \\
\hline
\end{tabular}

$\chi^{2}=34.974, \mathrm{df}=12, \mathrm{P}=0.000$.

Table 7. Distribution of HBV Status in relation to subject studied in Benue State, Nigeria.

\begin{tabular}{ccccc}
\hline \multirow{2}{*}{ Subject Type } & Number Tested & \multicolumn{3}{c}{ Infection Status } \\
\cline { 3 - 5 } & & Current Infection (\%) & Past Infection (\%) & Unexposed (\%) \\
\hline Pregnant Women & 507 & $38(7.5)$ & $383(75.5)$ & $86(17.0)$ \\
HCW & 255 & $27(10.6)$ & $190(74.5)$ & $38(14.9)$ \\
Blood Donor & 216 & $33(15.3)$ & $157(72.7)$ & $26(12.0)$ \\
Sex Workers & 154 & $26(16.9)$ & $105(68.2)$ & $23(14.9)$ \\
Acc. Victims & 260 & $42(16.2)$ & $173(66.5)$ & $46(17.7)$ \\
Patients & 143 & $18(12.6)$ & $107(74.8)$ & $17(11.9)$ \\
Total & 1535 & $184(12.0)$ & $1115(72.6)$ & $236(15.4)$ \\
\hline
\end{tabular}

$\chi^{2}=24.157, \mathrm{df}=10, \mathrm{P}=0.007$. 
Total exposure rate of $85.9 \%$ observed in this study is comparable to $76.6 \%$ and $85 \%$ reported by Belo [19] among surgeons in Lagos and Sanders et al. [20] in Papua New Guinea, respectively, while lower exposure rate of $57.0 \%$ was also reported by Belo [19] among the control subjects in Lagos. All these show that HBV is highly endemic in Benue as was concluded for Papua New Guinea.

The $22.5 \%$ of natural anti-HBs antibodies recorded among apparently healthy individuals (Table 3 ) indicates that a good number of previously HBV infected individuals in this study had their infection resolved naturally. This further suggests that the HBsAb can protect against re-infection [3] and hence efficacy of vaccination in prevention of the disease, desirably in Benue State.

The absence of any serologic marker (14.1\%) in the sample population of this work is low compared to $23.4 \%$ and 43.05\% report by Belo [19] among surgeons and the control subjects respectively in Lagos. These differences can be explained by variations in exposure rates obtainable in different demographic regions of Nigeria.

Occult HBV is used to explain the presence of HBV viraemia without HBsAg in the presence or absence of antibodies and can be identified by a molecular assay [21]. All forms of occult HBV could be infectious in immune-compromised individuals; but detection of HBVDNA in individuals with only HBcAb was associated with infectivity in both immuno-compromised and immuno-competent individuals, especially in blood transfusion [22]. Reports have also shown that occult HBV is common in $\mathrm{HBsAg}^{-}, \mathrm{HBcAb}^{+} \mathrm{HIV}$ infected patients and can be predicted by non detection of HBsAb [23]. This makes the 38.2\% HBcAb prevalence rates observed in our study a great public health concern. The prevailing situation where blood donors in most hospitals and laboratories are only screened for HBsAg, HIV, HCV and other factors but not for HBcAb in HBsAg negative donors means overlooking potential sources of HBV infection, the occult HBV individuals. This puts those undergoing immunosuppressive therapy and the immuno-compromised at great risk of infection [21]. Occult HBV have been detected in $7.2 \%$ of adult patients in Ibadan, Nigeria but none in the control group of the study [24]. Thabit et al. [21] reported 50\% of occult HBV among HBcAb positive individuals in Yemen.

Furthermore, the $38.2 \%$ prevalence rate of HBcAb recorded in the study is higher than the $11.4 \%$ reported by Sadoh and Sadoh [25] in Benin, Nigeria. But the difference in prevalence rates in the two studies may be explained by age difference of the two sample populations-Sadoh and Sadoh [25] studied infants while the study reported here sampled mainly adults. Sadoh and Sadoh [25] further explained that HBcAb antibodies are known to cross the placenta, thus, their presence in the infants studied may be an indication of transfer of maternal antibodies.

The $8.7 \%$ rate of acute HBV infection recorded in this study is lower than $64.3 \%$ reported by Bello et al. [26] in Sokoto, Nigeria. The difference may have come because in this study the only criterion inferring acute infection was presence of HBsAg and HBcIgM which may not be all inclusive. Rather, presence of HBcIgM in sera with HBsAg in the absence of HBeAg would denote a Chronic HBV carrier state as described earlier in this report. This advocates for a large panel of HBV markers in HBV infection classification rather than a few which may lead to misdiagnosis.

However, HBsAg and HBeAg determination in sera can be of immense contribution in the management of patients since HBeAg described the infectivity status of the patient as well as the persistence of the chronic HBV infection. Hence, 3.8\% of chronic HBeAg subjects in this study may be expected to have high chances of developing persistent liver disease leading to cirrhosis and even primary liver cancer if not treated [27] while 8.7\% of those acute if not well managed could also become chronic.

On the other hand, Hadziyannis and Vassilopoulos [28] have opined that individuals that are persistently HBeAg-negative may not necessarily be healthy carriers given that the immune pressure on the wild strain of HBV may lead to selection of HBeAg mutants. This also calls for further investigation of the Chronic HBeAg negative subjects in Benue State, Nigeria.

The higher, though not statistically significant ( $\mathrm{P}>0.05$ ), HBeAg, acute HBV infection and chronic HBeAg positive males subjects in this study may raise concern since males seems to be more prone to persistent HBV liver diseases, cirrhosis and primary liver cancer [29].

The very high rate of chronic infections (91.2\%) in this study compared with $14.1 \%$ reported by de Souza et al. [29] in Brazil could be attributed to highly endemic circulation of HBV in the sub-Saharan region as compared to Brazil, a region reported to have HBV low endemicity. This may further accounts for the higher cases of liver cancers reported in sub-Saharan Africa [3].

This study shows a low prevalence of HDV in Benue State, only 2.7\% among HBsAg-positive individuals screened but this would not distract from the findings of Nwokdiuko and Ijeoma [5] that 12.5\% of patients with 
various forms of HBV-related liver diseases also had antibodies to HDV. In their findings, $4.3 \%$ of the infected patients had asymptomatic or acute HBV infection and was significantly lower than those with chronic HB, liver cirrhosis and carcinoma with $15.0 \%$. It is therefore, not clear why, HDV was higher (6.2\%) among subjects with acute HB in this study than those with chronic hepatitis B (2.5\%). These findings indicate low endemicity of HDV in Nigeria compared to Gabon with HDV antibody prevalence of $63 \%-70 \%$ [4]. Strong association between HDV and blood transfusion ( $\mathrm{P}=0.002)$ in this study emphasizes need for safer blood transfusions in Benue State. The study could not explain why only women were infected with hepatitis delta virus.

The high current HBV infection rate $16.7 \%$ coupled with the high number of unexposed individuals (41.7\%) among subjects less than 13 years in this study suggest horizontal HBV transmission among this age group. Similarly high prevalence of past infection (92.9\%) coupled with the low proportion (7.1\%) of unexposed subjects recorded among persons 60 years and above is an indication that exposure to HBV in Benue State increases with age. This confirms Amazigo and Chime s' [30] report that by the age of 40 years, $87 \%$ of Nigerian population have at least one serologic marker.

HBV current infection of $7.5 \%$ recorded among pregnant women in this study shows a decrease from the $11.0 \%$ previously reported by Mbaawuaga et al. [8]. Similar sero-prevalence of $6.67 \%$ and $6.5 \%$ have been reported by Pennap et al. [31] in Keffi and Adagbara et al. [32] in Minna all in north central and North western Nigeria. While HBV prevalence appear to decrease among pregnant women in the North central states where HIV prevalence is persistently reported to be high [33], HBV prevalence of $11.5 \%, 12.5 \%, 16.5 \%$ and $6.08 \%$ have been reported by Okonko and Udeze [34] in Oluyoro, Ibadan, Ugbebor et al. [35] in Benin, Kolawole et al. [36] in Oshogbo and Rabiu et al. [37] in Lagos, respectively, in south western Nigeria. Almost all pregnant women identified at antenatal clinic in North central states are enrolled for highly active retroviral therapy (HAART) that is known to be therapeutically potent on both HIV and HBV. Thus, the decrease in HBV prevalence could be attributed to both the prophylactic and therapeutic effects of lamivudine, tenofovir containing regimens on HBV incidence in the North central states [38] [39]. This can be further explained looking comparatively at significantly $(\mathrm{P}<0.05)$ lower $7.5 \%$ among pregnant women as against other groups in this study that may not have been closely monitored. But this study could not explain why lower HBV prevalence were observed among antenatal attendees in this study compared with their counterpart in South Western Nigeria that are reported to be more literate.

Conclusively, there are apparently healthy persons with acute and chronic HBV and HDV infection who may serve as source of infection to others. This calls for a government organized Hepatitis Programme to treat cases of acute and chronic hepatitis and roll out strategy for preventing the spread of HBV infections in Benue State, Nigeria.

\section{Acknowledgements}

We are indebted to Dr. J. Aper, Rt. Hon. H. Amena and Mr. I. Ikyereve for their financial assistance. We thank TETFUND office for being the major sponsor of this work.

\section{References}

[1] Hoffman, C.J. and Thio, C.L. (2007) Clinical Implications of HIV and Hepatitis B Co-Infection in Asia and Africa Review. The Lancet Infectious Disease, 7, 402-409. http://dx.doi.org/10.1016/S1473-3099(07)70135-4

[2] Carey, I., D’Antiga, L., Bansal, S., Longhi, M.S., Ma, Y., Mesa, I.R., Mieli-Vergani, G. and Vergani, D. (2011) Immune and Viral Profile from Tolerance to Hepatitis B Surface Antigen Clearance: A Longitudinal Study of Vertically Hepatitis B Virus Infected Children on Combined Therapy. Journal of Virology, 85, 2416-2428. http://dx.doi.org/10.1128/JVI.01449-10

[3] WHO/CDS/CSR/LYO (2002) Hepatitis B. http://www.who.int/emc

[4] Niro, G.A., Fontana, R., Ippolito, A.M. and Andriulli, A. (2012) Epidemiology and Diagnosis of Hepatitis D Virus. Future Virology, 7, 709-717. http://dx.doi.org/10.2217/fvl.12.61

[5] Nwokediuko, S.C. and Ijeoma, U. (2009) Seroprevalence of Antibody to HDV in Nigerians with Hepatitis B Virus-Related Liver Diseases. Nigerian Journal of Clinical Practice, 12, 439-442.

[6] Federal Government Population Gazette (2009) Federal Republic of Nigeria. 96, 2.

[7] Hilhorst, T., Liere, M.J., Ode, A.V. and de Koning, K. (2006) Impact of AIDS on Rural Livelihoods in Benue State, 
Nigeria. Journal of Social Aspects of HIV/AIDS, 3, 382-393. http://dx.doi.org/10.1080/17290376.2006.9724864

[8] WMA (2008) World Medical Association Declaration of Helsinki-Ethical Principle for Medical Research Involving Human Subjects. 59th WMA General Assembly, Seoul, October 2009.

http://www.wma.net/en/30publicatons/10policies/b3/index.html

[9] Mbaawuaga, E.M., Enenebeaku, M.N.O., Okopi, J.A. and Damen, J.G. (2008) Hepatitis B Virus (HBV) Infection among Pregnant Women I Makurdi, Nigeria. African Journal of Biomedical Research, 11, 155-159.

[10] Mbaawuaga, E.M., Nor, J.S. and Jombo, G.T.A. (2008) Prevalence of Hepatitis B Surface Antigen (HBsAg) among Patients in Makurdi, Benue State. The Nigerian Journal of Pure Applied Science, 1, 48-53.

[11] Alao, O.O., Okwori, E.E., Egwu, C. and Audu, F. (2009) Seroprevalence of Hepatitis B Surface Antigen among Prospective Blood Donors in an Urban Area of Benue State. The Internet Journal of Hematology, 5, 12.

[12] Amuta, E.U., Houmsow, R.S., Sar, T.T. and Awodi, E.M. (2012) Seroprevalence of Hepatitis B among Hospital Patients in Makurdi Metropolis, Benue State, Nigeria. International Journal of Biology, Pharnacy and Allied Sciences, 1, 29-35.

[13] Odimayo, M.S., Adediran, S.O. and Araoye, M.O. (2010) Socio-Demographic Characteristics of Adults Screened for HIV/AIDS in Rural Community in Benue State, Nigeria. African Journal of clinical and Experimental Microbiology, 11, 129-136.

[14] Sule, W.F., Okonko, I.O., Yumusa, I.P., Odu, N.N. and Frank-Peterside, N. (2011) Hepatitis B Surface Antigen (HBsAg) and Risk Factors of Transmission among Patients Attending Hospital in Ankpa, Kogi State, Nigeria. Nature and Science, 9, 37-41.

[15] Forbi, F.C., Onyemauwa, N., Gyar, S.D., Oyeleye, A.O., Entonu, P. and Agwale, S.W. (2008) High Prevalence of Hepatitis B Virus among Female Sex Workers in Nigeria. Revista do Instituto de Medicina Tropical de São Paulo, 50, 219-221.

[16] Adoga, M.P., Edmund, B.B., Forbi, J.C., Nimzing, L., Pam, C.R., Gyar, S.D., Agabi, A.Y. and Agwale, S.M. (2009) Human Immunodeficiency Virus, Hepatitis B Virus and Hepatitis C Virus Seroprevalence, Co-Infection and Risk Factors among Prison Inmates in Nasarawa State, Nigeria. Journal of Infections in Developing Countries, 3, 539-547. http://dx.doi.org/10.3855/jidc.472

[17] Egah, D.Z., Banwat, E.B., Audu, E.S., Iya, D., Mandong, B.M., Anele, A.A. and Gomwalk, N.E. (2005) Hepatitis Surface Antigen, Hepatitis C and HIV Antobodies in Low Risk Blood Donor Group, Nigeria. Eastern Mediterranean Health Journal, 13, 1-6.

[18] Uneke, C.J., Ogbu, O., Inyama, P.U., Anyanwu, G.I., Njoku, M.O. and Idoko, J.H. (2005) Prevalence of Hepatitis b Surface Antigen among Blood Donors and Human Immunodeficiency Virus-Infected Patients in Jos, Nigeria. Memorias do Instituto Oswaldo Cruz Rio de Janeiro, 100, 13-16.

[19] Belo, A.C. (2000) Prevalence of Hepatitis B Virus Markers in Surgeons in Lagos, Nigeria. East African Medical Journal, 77, 283-285.

[20] Sanders, R.C., Lewis, D., Dyke, T. and Alpers, M.P. (1992) Markers of Hepatitis B Infection in Tari District, Suthern Highlands Province, Papua New Guinea. PNG Medical Journal, 35, 197-201.

[21] Thabit, A.M., Al-Moyed, K.A., Al-Balushi, M.S., Hasson, S.S. and Sallam, T.A. (2012) Occult Hepatitis B Virus among Chronic Liver Disease Patients in Yemen. Asian Pacific Journal of Tropical Diseases, 2, 4-6.

[22] Allain, J.P. (2004) Occult Hepatitis B Virus Infection: Implications in Transfusion. Vox Sang, 86, 83-91. http://dx.doi.org/10.1111/j.0042-9007.2004.00406.x

[23] Nebia, G., Gracia-Diaz, A., Ayliffe, U., Smith, C., Dervisevic, S., Johnson, M., Gilson, R., Tedder, R. and Geretti, A.M. (2007) Predictors and Kinetics of Occult Hepatitis B Virus Infection in HIV Infected Persons. Journal of Medical Virology, 79, 464-471.

[24] Ola, S.O., Otegbayo, J.A., Olaleye, D.O., Olubuyide, I.O., Summerton, C.B. and Bamgboye, E.A. (2009) Occult HBV Infection among a Cohort of Nigerian Adults. Journal of Infections in Developing Countries, 3, 442-446. http://dx.doi.org/10.3855/jidc.415

[25] Sadoh, A.E. and Sadoh, W.E. (2013) Serological Markers of Hepatitis B Infections in Infants Presenting for Their First Immunization. Nigeria Journal of Pediatrics, 40, 248-253.

[26] Bello, H.S., Isa, M.A., Shettima, A. and Allamin, I.A. (2013) Prevalence of Serological Markers for Acute Hepatitis B Virus among Patients Attending Sokoto Specialist Hospital, Sokoto, Nigeria. Journal of Microbiology and Biotechnology Research, 3, 132-135.

[27] Tonetto, P.A., Goncales, N.S.L., Fais, V.C., Vagani, A.G., Goncales, E.S.L., Feltrin, A. and Goncales, F.L. (2009) Hepatitis B Virus: Molecular Genotypes and HBeAg Serological Status among HBV-Infected Patients in the Southeast of Brazil. BMC Infectious Diseases, 9, 149. http://www.biomedcentral.com/1471-2334/9/149 
[28] Hadziyannis, S.J. and Vassilopoulos, D. (2001) Immunopathgenesis of Hepatitis Be Antigen Negative Chronic Hepatitis B Infection. Antiviral Research, 52, 91-98. http://dx.doi.org/10.1016/S0166-3542(01)00173-5

[29] De Souza, L.A., Demattas, A.A., Fiorini, M., Ribeiro, P. and Tovo, C.V. (2013) Clinical Outcome of a Patient Cohort with Acute Hepatitis B. Clinic (Sao Paulo), 68, 718-720. http://dx.doi.org/10.6061/clinics/2013(05)21

[30] Amazigo, U.O. and Chime, A.B. (1990) Hepatitis B Virus Infection in Rural and Urban Populations of Eastern Nigeria: Prevalence of Serological Markers. East African Medical Journal, 67, 539-544.

[31] Pennap, G.R., Osanga, E.T. and Ubam, A. (2011) Seroprevalence of Hepatitis B Surface Antigen among Pregnant Women Attending Antenatal Clinic in Federal Medical Centre Keffi, Nigeria. Research Journal of Medical Science, 5, 80-82.

[32] Adagbara, N.U., Ajala, O.O., Momohjimoh, A., Hashimu, Z. and Agabi, A.Y.V. (2012) Prevalence of Hepatitis B Virus among Women Attending Antenatal Clinic in the General Hospital Minna, Niger State. Shiraz E-Medical Journal, 13.

[33] Federal Ministry of Health (FMOH) (2010) National HIV Seroprevalence Sentinel Survey. www.nigeria-aids.org/documents/2010_NationalHIVSeroPrevalence SentinelSurvey.pdf

[34] Okonko, I.O. and Udeze, A.O. (2011) Detection of Hepatitis b Surface Antigen (HBsAg) among Pregnant Women Attending Antenatal Clinic of O.L.A Catholic Hospital, Oluyoro, Ibadan, Oyo State, Southwest Nigeria. Nature and Science, 9, 54-60.

[35] Ugbebor, O., Aigbinor, M., Osazuwa, F., Enabudoso, E. and Omorogbe, Z. (2012) The Prevalence of Hepatitis B and C Viral Infections among Pregnant Women. North American Journal of Medical Science, 3, 238-241.

[36] Kolawole, O.M., Wahab, A.A., Adekanle, D.A., Sibanda, T. and Okoh, A.I. (2011) Seroprevalence of Hepatitis B Surface Antigenemia and Its Effects on Hematological Parameters Inpregnant Women in Oshogbo, Nigeria. Virology Journal, 9, 317. http://www.virologyj.com/content/9/1/317

[37] Rabiu, K.A., Akinola, O.I., Adewunmi, A.A., Omololu, O.M. and Ojo, T.O. (2010) Risk Factors of Hepatitis B Virus Infection among Pregnant Women in Lagos, Nigeria. Acta Obstetric and Gynecology Scand, 89, 1024-1028. http://dx.doi.org/10.3109/00016349.2010.482580

[38] Gatanaga, H., Hayashida, T., Tanuma, J. and Oka, S. (2013) Prophylactic Effect of Antiretroviral Therapy on Hepatitis B Virus Infection. Clinical Infectious Disease, 56, 1812-1819. http://dx.doi.org/10.1093/cid/cit145

[39] Benhamou, Y., Fleury, H., Trimoulet, P., Pellegrin, I., Urbinelli, R., Katlama, C., Rozenbaum, W., le Teuff, G., Trylesinki, A. and Piketty, C. (2006) Anti-Hepatitis B Virus Efficacy of Tenofovir Disoproxil Fumarate in HIV-Infected Patients. Hepatology, 43, 548-555. http://dx.doi.org/10.1002/hep.21055 